- who launched the pig biobank.

Only a few animal biobanks have so far been built, and most are for mice. Pigs, although more expensive to house and breed, could be more useful because of their larger size and the greater similarity of their physiology and metabolism to those of humans.

To create the pig biobank, scientists used genetic engineering and cloning techniques to create animals with a damaged gene called MIDY, which means that they need a daily insulin injection. The animals were then bred with healthy pigs so that, on average, half of the second-generation litters had diabetes and the other half were healthy, and thus able to serve as experimental controls.

The 12th addition to the bank from this process, Boar 1339 was already anaesthetized when it arrived in the cavernous autopsy room of the 101-year-old veterinary school in a leafy suburb of Munich. Waiting for the pig was a team of 25 veterinary surgeons and technicians, gowned up, masked and alert at parallel dissection tables.

A hoist raised the pig by its hind legs and pathologists injected the animal with a lethal dose of anaesthetic. Then, in swift, precision choreography, the team moved in with their knives, cleavers, hammers and pincers. They removed organs, muscles, nerves and more, and transferred the tissues to the tables at which the waiting dissectors set about their complicated sampling process, strictly following an 80-page protocol. "We don't want to complete a super-sophisticated sampling and then realize we forgot to weigh the liver," says Andreas Blutke, one of the chief pathologists at the LMU. The chopping, hacking and puncturing are loud; the concentration of the workers

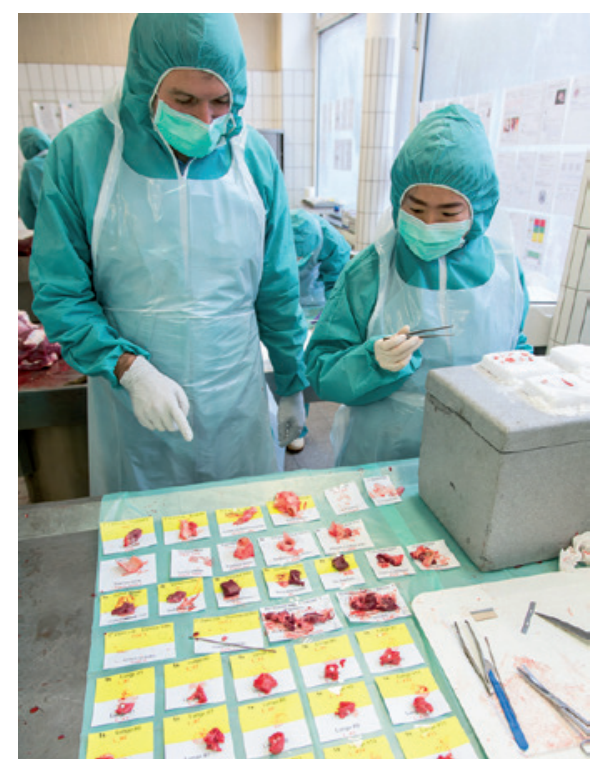

Samples enable structural and molecular analysis.

keeps the background noise to a murmur. The whole process takes a mere 2 hours 15 minutes.

Because the cells in any organ are of different sizes, shapes and orientations, and are unevenly distributed, the team takes numerous samples using different methods to ensure that the whole organ is appropriately represented. The system is so sophisticated that it gives researchers a three-dimensional anatomical reconstruction of the exact cell types.

Crucially, the researchers divide each sample and preserve the portions in different ways, each optimized for either structural or molecular analysis. This allows both types of analysis to be done on the same sample. "I think this is the only service which allows you to do molecular profiling and cellular anatomy from the same sample," says Wolf.

As soon as Rorsman heard about the biobank, he saw its benefit. He suspects that the long-term complications of diabetes are caused by changes in a particular molecule in the cells of several different tissues. Material from the biobank will allow him to confirm that he is on the right track, he says, before he obtains samples from human biobanks, which takes a long time because of ethical constraints. Herbert Tempfer, a diabetes researcher at the University of Salzburg in Austria, is already analysing samples of tendons - notoriously fragile in people with diabetes - from the biobank.

Others want to know how similar pig diabetes is to the human disease. Immunologist Åsa Hidmark at the University of Heidelberg in Germany made the three-hour journey to Boar 1339's dissection to cut samples of skin from its trotter. She hopes to discover that the nerve endings in the outer layer have been lost, as happens in people with diabetes.

The ultimate value of the bank will depend on how much it is used - and there are no guarantees. Despite its collection of 42 tissues taken from 940 mouse lines, a mouse biobank at the Wellcome Trust Sanger Institute near Cambridge, UK, has so far received only 50 or so requests for material. "There is a lack of awareness of its value," says Jacqui White, who leads this Sanger mouse-autopsy project.

Wolf plans to extend his biobank to other genetic pig models as they are developed. Next in line are probably pigs engineered to have Duchenne muscular dystrophy. A sow implanted with a cloned genetically modified embryo is now pregnant.

\title{
Climate modellers take tropical approach
}

Ten-year US-led project seeks to plug gaps in global-warming simulations.

\section{BY JEFF TOLLEFSON}

$\mathrm{T}$ The US Department of Energy has approved a campaign to better understand the response of tropical forests to rising levels of atmospheric carbon dioxide. The experiments are designed to improve global climate simulations and to determine whether the increased tropical-forest growth caused by carbon dioxide enrichment will partially offset global warming.
The US\$96-million Next-Generation Ecosystem Experiment for the tropics, NGEE Tropics, builds on an ongoing project in the Arctic that has put climate modellers into the field with ecologists, biologists and hydrologists to improve understanding of the fate of permafrost in a warming world. The department plans to announce the new programme within weeks.

Focusing on the future of tropical forests and their role in regulating the global climate, the ten-year tropical programme will begin with pilot studies at sites in Puerto Rico, Panama and Brazil, and then expand into other areas, including Africa and southeast Asia. Although ecologists have studied tropical ecosystems intensively, the new experiments will be designed to plug specific gaps in climate models.

"The whole point is getting data that is appropriate for working with models," says Richard Norby, an ecologist at the Oak Ridge National Laboratory in Tennessee, who is 
involved in the project. "I think the days of doing independent experiments and then just publishing data and seeing if somebody picks it up are over. And they should be over."

Climate models suggest that tropical forests could significantly offset human carbon emissions - or not - depending on whether the forests grow faster as atmospheric carbon dioxide concentrations rise. Experiments in northern temperate forests suggest that the increase will have some growth-stimulating effect as plants take up some of the extra carbon dioxide through photosynthesis and incorporate it into wood and other biomass, but that additional growth may be limited by the availability of other nutrients, such as nitrogen.

In a pilot study in Puerto Rico, ecologists will investigate below-ground biogeochemistry and soil fertility in combination with aerial imaging to see how these processes affect leaf chemistry. A site in Brazil will focus on daily and seasonal soil-moisture changes to better understand how tropical forests respond to droughts. A third pilot project, in Panama, will look at various plant traits and how they are represented in the models.

The tropical campaign follows the launch in 2012 of a similar project in the Arctic designed to determine the extent to which the melting of permafrost due to warming will release vast stores of carbon buried for thousands of years. Most climate models include only a crude representation of the tundra, treating permafrost as a single uniform layer that responds uniformly to increases in temperature. In reality, permafrost is a patch-

\section{"The whole point is getting data that is appropriate for working with models."} work of ice wedges and troughs that break up the landscape into countless polygons. As ice melts, the troughs expand and widen and new ones open up, which hastens further melting and decomposition of organic material.

"If it was a simple landscape that was responding linearly, you could get away with those simple representations," says Peter Thornton, a climate modeller at Oak Ridge who heads the modelling component of the Arctic project. "But the distribution of these ice wedges is regularly patterned and that forces dynamics at these fine scales that are completely nonlinear."

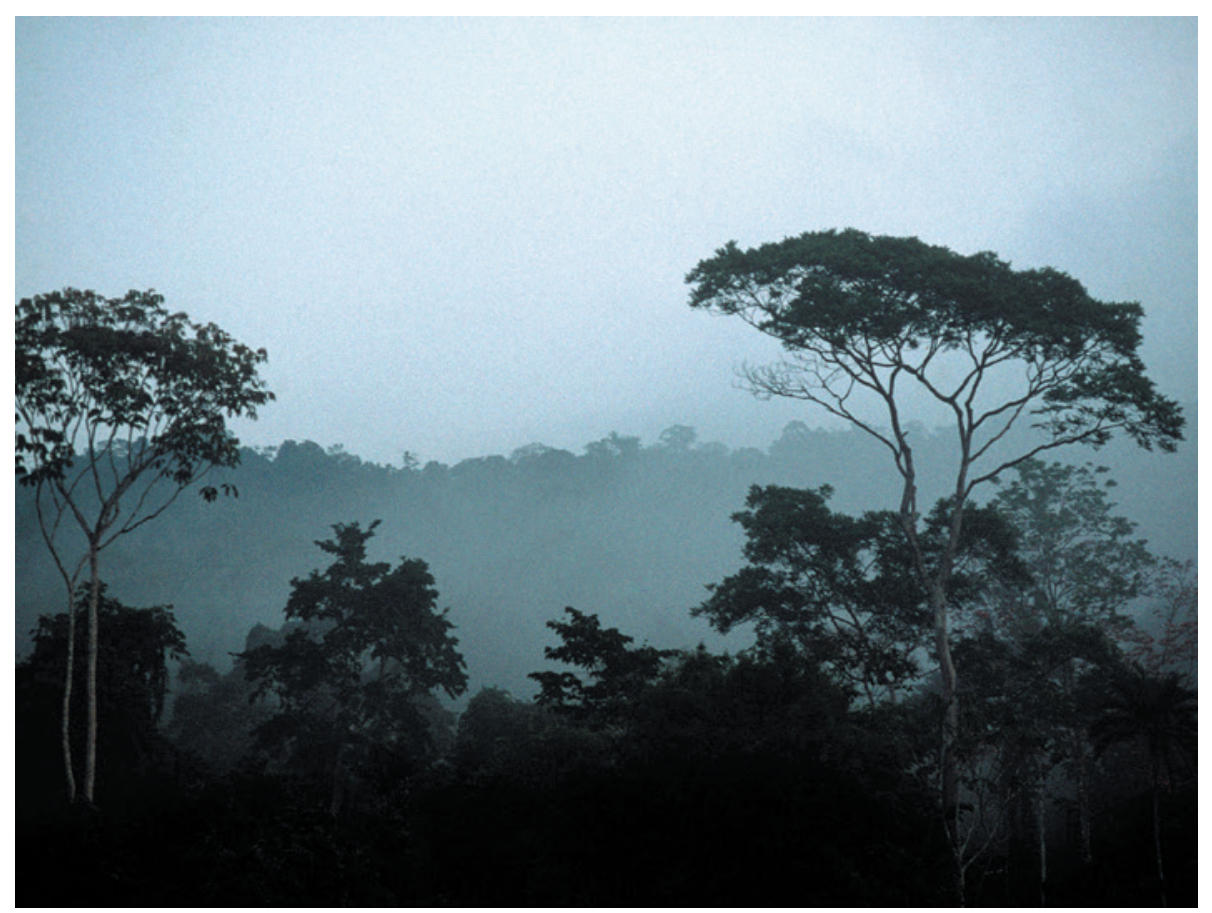

Tropical forests will respond to rising carbon dioxide in ways that are hard to predict with climate models.

Since the Arctic project began, scientists have drilled boreholes into ice wedges and troughs at the site near Barrow, Alaska, to get a sense of how water and heat penetrate the permafrost layers. The goal is to understand how fast the microbes in thawing permafrost will break down vast stores of organic matter that have been stored in the soil for millennia. That process releases methane, a potent greenhouse gas. Ice cores are being analysed and subjected to heating experiments at the Lawrence Berkeley National Laboratory in Berkeley, California, to uncover how different microbes respond.

In other field experiments, biologist Alistair Rogers at the Brookhaven National Laboratory in New York analysed rates of photosynthesis in a variety of Arctic plants. From these real measures, Rogers found that even the handful of climate models that do include explicit vegetation types underestimate the photosynthetic potential in the Arctic by a factor of three to five.

Modellers and field scientists have gradually grown further apart as the scientific disciplines have become increasingly complex, but this new approach seems to be reversing that trend, says Ted Schuur, an ecologist at the University of Florida in Gainesville, who is a reviewer on the NGEE Arctic programme. Although it is still early in the project, he says, "the way they have organized their pipeline really points toward success".

The challenge for modellers is how to simulate ecological processes that take place at the scale of microbes and plants within global models comprised of grids of squares up to 100 kilometres on a side. Thornton's team is working on new models that bridge the gap between those vastly different scales in the Arctic. These will be integrated into a new climate model under development by the energy department.

Scientists will take a similar approach in the tropics. They have already begun to assess climate models to identify weaknesses and gaps in how they represent tropical ecosystems.

In addition to improving climate models, the effort will produce new advances in basic science, says Jeff Chambers, a tropical ecologist at the Lawrence Berkeley National Laboratory and director of the NGEE Tropics project. "It's a fantastic opportunity, and there's plenty of room for discovery science along the way."

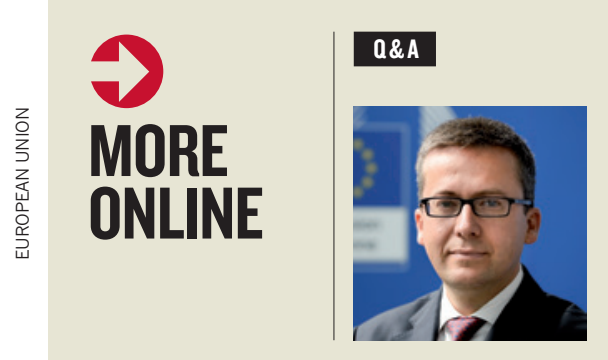

Europe's

research commissioner lays out his ambitions go.nature.com/ fvaflf

\section{TOP NEWS}

- Mystery of Darwin's 'strange animals' solved go.nature.com/yiej2j - Surprise dust cloud spotted billowing over Mars go.nature.com/aql2en - China and Europe pore over joint space-mission proposals go.nature.com/ycbndn

\section{VIDEO}

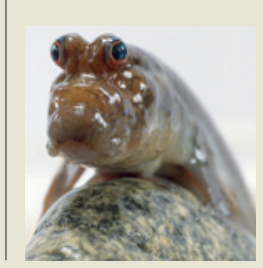

How the mudskipper fish uses a 'water tongue' to grab prey on land go.nature. com/uqdp13 